Environment Protection Engineering

Vol. 42

2016

No. 3

DOI: $10.5277 /$ epe 160306

\title{
DECOMPOSITION OF POLLUTANTS \\ IN TEXTILE WASTEWATER DURING THE FENTON PROCESS IN THE PRESENCE OF IRON NANOCOMPOUNDS
}

\begin{abstract}
The efficiency of the decomposition of pollutants in textile wastewater has been determined by the Fenton method in the presence of iron nanocompounds and the results have been compared with those by the classical Fenton method. The wastewater was purified with ferrous sulfate and ferrous sulfate with the addition of iron(II, III) nanocompound. The effect of optimization of the process was examined by adding various amounts of ferrous sulfate and iron(II, III) nano-oxide, hydrogen peroxide and changing $\mathrm{pH}$ of the solution. It was found that addition of iron nano-oxide in the presence of ferrous sulfate increased the efficiency of pollutant decomposition in the wastewater.
\end{abstract}

\section{INTRODUCTION}

Textile wastewater is classified as difficult for treatment. This is due to a significant amount of wastewater produced, its diversified composition, big load of organic and mineral impurities, high toxicity and poor biodegradability. Characteristic features of textile wastewater are its intensive and changing colors as well as high content of surfactants and other organic chemical compounds of different character and structure used in textile finishing processes. Hence, methods to ensure effective textile wastewater treatment are still searched for. These methods include a group of so-called advanced oxidation processes (AOPs). There are many versions of these processes whose common feature is the formation of hydroxyl radicals with a high oxidation potential and then their application in the oxidation of impurities contained in water. $\mathrm{HO}$ radicals are generated in various ways such as a result of the reaction of ozone and water, photolysis, hydrogen peroxide decomposition, in the Fenton reaction, photocatalysis in the presence of titanium dioxide, radiation, etc. [1-5].

${ }^{1}$ Textile Research Institute, ul. Brzezińska 5/15, 92-103 Łódź, Poland, corresponding author L. Kos, e-mail: 1kos@iw.lodz.pl 
High reactivity of hydroxyl radicals and their low selectivity enables oxidation of large groups of organic compounds occurring in the wastewater, in this number dyes and detergents. At the same time it makes the method applicable in the wastewater of varying composition and content of pollutants which is a characteristic feature of textile wastewater. An additional advantage of the method is the lack of secondary pollution of the environment and no risk of overdosing oxidizing agents.

Among AOPs methods especially often used is the Fenton method which takes advantage of the oxidizing action of hydroxyl radicals generated in the chain process of hydrogen peroxide decomposition in the presence of bivalent iron salts. Besides oxidation, the Fenton process includes also the process of coagulation related to the precipitation of iron(III) hydroxide. Due to this, textile wastewater can be significantly decolorized and the main load of organic impurities can be removed [6-10]. The advantage of the Fenton process is efficient decomposition of pollutants, simple technology and low costs of the method.

New trends in the researches on pollutant oxidation processes by the Fenton method cover the application of iron nanocompounds in the reaction system. Their presence has an effect on the oxidizing reaction of chemical compounds present in the wastewater [11-14]. Iron nanocompounds exhibit catalytic activity which increases the effectiveness of oxidizing processes. Also other metal nanocompounds are active in supporting pollutant decomposition in the Fenton processes carried out with the use of iron nanocompounds $[15,16]$. Owing to this, harmful chemical compounds such as trichloroethylene, phenol, dyes, humic acids, antibiotics, metals and hormones decompose faster and with better efficiency [17-20].

The aim of researches presented in this paper was to determine the efficiency of decomposition of pollutants occurring in textile wastewater during the Fenton process in the presence of iron nanocompounds as compared to the classical Fenton process.

\section{METHODS}

Subject of studies. The tested material was textile wastewater generated during dyeing of cellulose fibers. The wastewater contained azo dyes, a non-ionic surfactant, acetic acid, sodium carbonate and sodium chloride. The wastewater had an intensive red color, its COD was $305 \mathrm{mg} \mathrm{O} / \mathrm{dm}^{3}$, TOC was $97 \mathrm{mg} / \mathrm{dm}^{3}$ and initial $\mathrm{pH}$ was 10.6 .

Experimental procedure. Analytically pure ferrous sulfate $\mathrm{FeSO}_{4} 7 \mathrm{H}_{2} \mathrm{O}$ and $30 \%$ hydrogen peroxide $\mathrm{H}_{2} \mathrm{O}_{2}$ (Chempur, Piekary Śląskie), iron(II, III) oxide nanopowder $<50 \mathrm{~nm}$ (Sigma Aldrich) as well as $\mathrm{H}_{2} \mathrm{SO}_{4}$ and analytically pure $\mathrm{NaOH}$ (POCh, Gliwice) were used in the experiments.

The $\mathrm{pHs}$ of wastewater were reduced to 4.0, 3.5, 3.0, 2.5 and 2.0 with $2.5 \mathrm{M}$ sulfuric acid solution. Next, samples were completed either exclusively with ferrous sulfate or 
jointly with ferrous sulfate and iron(II, III) oxide nanopowder in the solid state and the solution was stirred until complete dissolution. Then $30 \%$ solution of hydrogen peroxide was added dropwise to the wastewater. Once $\mathrm{H}_{2} \mathrm{O}_{2}$ had been added, the wastewater was stirred vigorously for $2 \mathrm{~min}$ and then slowly for the next $10 \mathrm{~min}$. The wastewater was left for $24 \mathrm{~h}$. Then the samples were neutralized with $10 \%$ solution of $\mathrm{NaOH}$ to $\mathrm{pH}$ about 11. After $24 \mathrm{~h}$, the wastewater was decanted and filtered.

The experiments were carried out using ferrous sulfate dose ranging from 0.1 to $0.75 \mathrm{~g} / \mathrm{dm}^{3}$ with iron nano-oxide from 0.01 to $0.05 \mathrm{~g} / \mathrm{dm}^{3}$. The weight ratio of iron nano-oxide to ferrous sulfate changed from 1:2 to 1:75. Hydrogen peroxide doses ranged from 1 to $7 \mathrm{~cm}^{3} / \mathrm{dm}^{3}$.

Analytical control. After the treatment, the color of wastewater was determined by the DFZ method. the spectral absorption coefficient (DFZ, German Durchsichtsfarbzahl) was determined by the spectrophotometric method at three wavelengths $\lambda$ (436, 525 and $620 \mathrm{~nm}$ ), according to the DIN-38404/1 standard, using the formula

$$
D F Z=\frac{1000 E(\lambda)}{d}
$$

where $E(\lambda)(1 / \mathrm{m})$ is the absorbance at a given wavelength $\lambda$, and $d$ is the measuring cuvette thickness (mm), $d$ being $10 \mathrm{~mm}$ in the present measurements. The UV-Vis absorption spectrum of the raw textile wastewater is shown in Fig. 1.

Chemical oxygen demand (COD) and total organic carbon (TOC) were determined by the Hach-Lange tests.

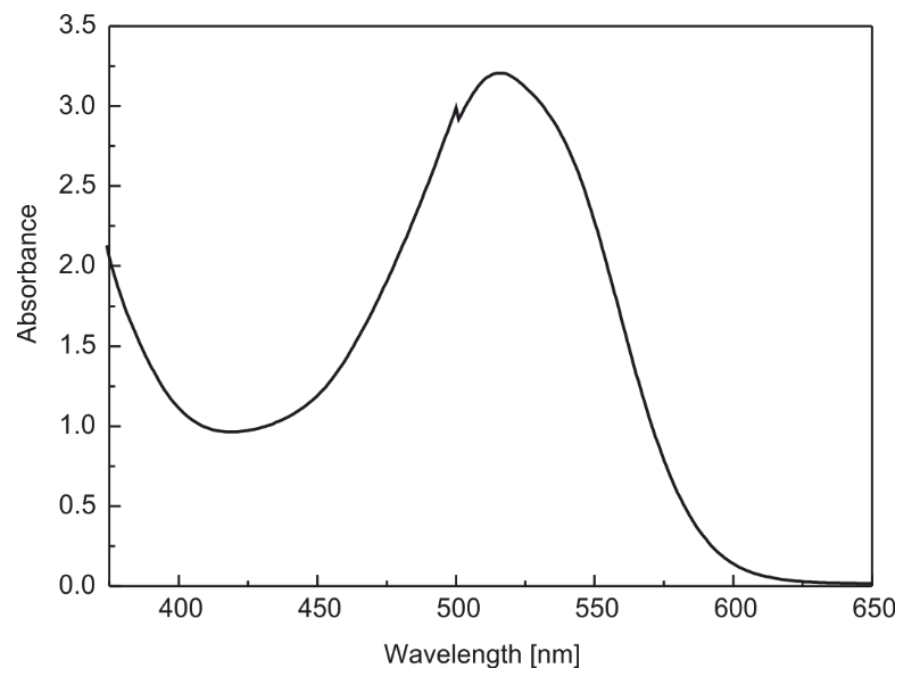

Fig. 1. UV-Vis absorption spectrum of the raw textile wastewater 


\section{RESULTS AND DISCUSSION}

\subsection{THE EFFECT OF IRON NANO-OXIDE DOSE}

Irrespective of the amount of iron nano-oxide added, the wastewater was very well decolorized with color reduction reaching from 95 to $99 \%$. The factor which was decisive for the decolorization efficiency was the amount of ferrous sulfate, while the dose of iron nano-oxide ranging from 0.01 to $0.05 \mathrm{~g} / \mathrm{dm}^{3}$ had practically no significance. This resulted probably from the fact that at the used treatment parameters the obtained decolorization degrees were high in general. The best results of decolorization reaching $99 \%$ were obtained at the smallest used amount of ferrous sulfate, i.e. $0.1 \mathrm{~g} / \mathrm{dm}^{3}$. Since the wastewater displayed absorption maximum at $525 \mathrm{~nm}$ (Fig. 1), the absorbances were measured at this wavelength. The results of studies on wastewater decolorization are shown in Fig. 2.

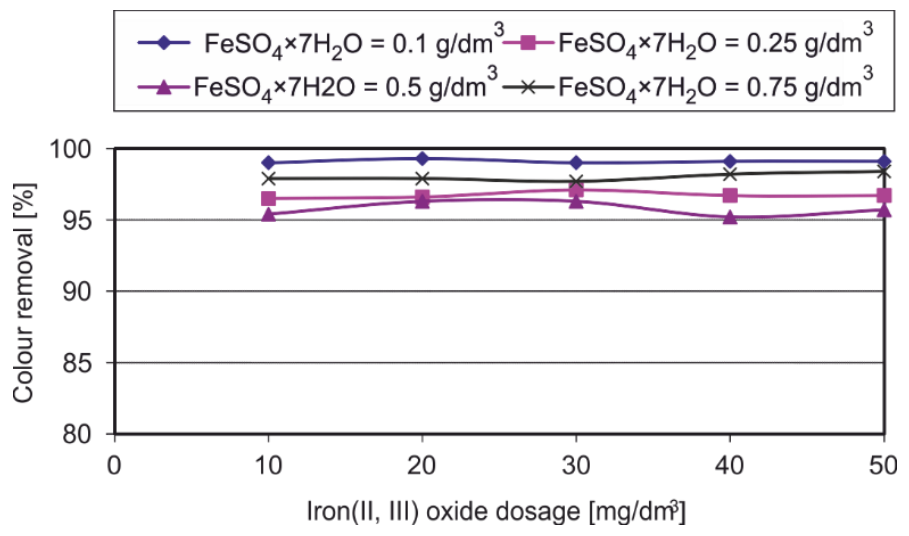

Fig. 2. Effect of ferrous sulfate and iron nano-oxide doses on color removal in the wastewater in the nanoFenton process: $\mathrm{H}_{2} \mathrm{O}_{2}$ dose $-5 \mathrm{~cm}^{3} / \mathrm{dm}^{3}$, initial absorbance $-3120(525 \mathrm{~nm}), \mathrm{pH}-3.5$

Contrary to the decolorization experiments, the COD reduction depended on the doses of both ferrous sulfate and iron nano-oxide (Fig. 3). COD reduction increased upon increasing amount of iron nano-oxide. However, differences in the COD reduction were insignificant, reaching several percent only. Optimum doses of iron nano-oxide ranged from 0.02 to $0.03 \mathrm{~g} / \mathrm{dm}^{3}$, the best COD reduction was obtained at smaller doses of ferrous sulfate, i.e. $0.1 \mathrm{~g} / \mathrm{dm}^{3}$. Probably at bigger amounts, when the added ferrous sulfate exceeded an optimum dose, the observed decrease of the oxidation efficiency was related to the decrease of the amount of hydroxyl radicals in the reaction medium. At high concentrations ferrous ions can act as scavengers of hydroxyl radical according to the reaction:

$$
\mathrm{Fe}^{2+}+\mathrm{HO}^{\bullet} \rightarrow \mathrm{Fe}^{3+}+\mathrm{HO}^{-}
$$




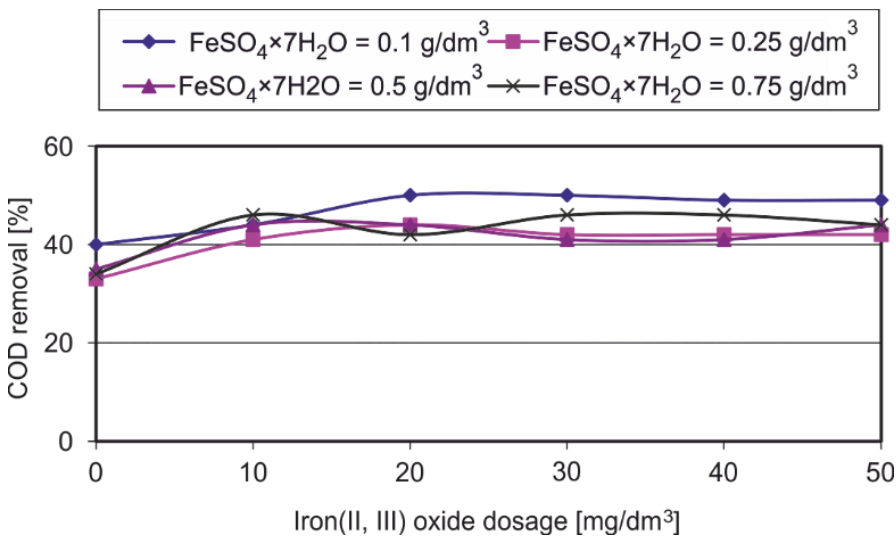

Fig. 3. Effect of ferrous sulfate and iron oxide nanopowder doses on COD removal in the wastewater in the nanoFenton process: $\mathrm{H}_{2} \mathrm{O}_{2}$ dose $-5 \mathrm{~cm}^{3} / \mathrm{dm}^{3}$, initial COD $-305 \mathrm{mg} \mathrm{O} / \mathrm{dm}^{3}, \mathrm{pH}-3.5$

The TOC values depended mainly on the doses of ferrous sulfate. The quantity of iron nano-oxide added at a constant dose of ferrous sulfate had only a slight effect on the TOC reduction (Fig. 4). Similarly as in COD, the highest TOC reduction was obtained at the lowest applied dose of ferrous sulfate, i.e. in the range from 0.1 to $0.25 \mathrm{~g} / \mathrm{dm}^{3}$.

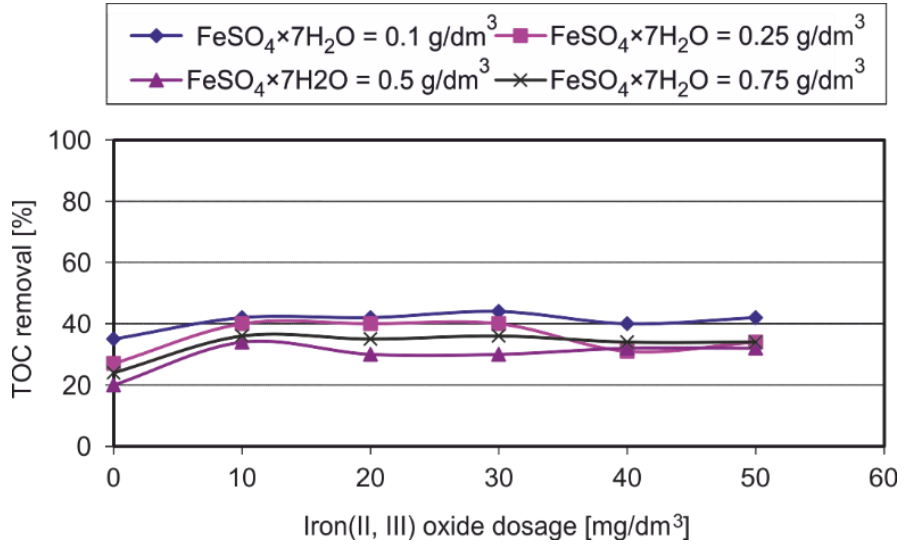

Fig. 4. Effect of ferrous sulfate and iron oxide nanopowder doses on TOC removal in the wastewater in the nanoFenton process:

$\mathrm{H}_{2} \mathrm{O}_{2}$ dose $-5 \mathrm{~cm}^{3} / \mathrm{dm}^{3}$, initial TOC $-97 \mathrm{mg} / \mathrm{dm}^{3}, \mathrm{pH}-3.5$

In summary, it should be noted that in the nanoFenton process the results of treatment were satisfactory which was confirmed by a practically complete wastewater decolorization as well as COD and TOC reduction. However, low-molecular oxidation products such as formic and acetic acids with low susceptibility to the Fenton reagent 
remained probably in the solution [21,22]. Literature data suggest that by the action of hydroxyl radicals on organic compounds including macromolecular compounds present in the wastewater, most of them is oxidized with decomposition products formed as low molecular compounds. Some of them undergo further oxidation which results in their mineralization. However, in the solution remain low molecular compounds resistant to the Fenton reagent, which include, among others, formic and acetic acid. It can be assumed with high probability that a similar mechanism occurs in the case of textile wastewater treated with Fenton reagent. The obtained TOC reduction was lower by a few to several percent than COD reduction which confirmed the statement that organic products of pollutant oxidation remained in the solution.

\subsection{THE EFFECT OF HYDROGEN PEROXIDE DOSAGE}

Besides ferrous sulfate the treatment efficiencies depended also on the amount of hydrogen peroxide present in the system. Table 1 shows results of decolorization depending on the applied dose of iron nano-oxide at various amounts of hydrogen peroxide at a constant dose of ferrous sulfate of $0.1 \mathrm{~g} / \mathrm{dm}^{3}$. Irrespective of the amount of iron nano-oxide and hydrogen peroxide, the wastewater was very well decolorized, with color reduction from 99 to $100 \%$.

Table 1

Color removal [\%] of wastewater in the nanoFenton process depending on the $\mathrm{H}_{2} \mathrm{O}_{2}$ dose

\begin{tabular}{|c|c|c|c|c|c|c|}
\hline \multirow{2}{*}{$\begin{array}{c}\text { Dose of } \mathrm{H}_{2} \mathrm{O}_{2} \\
{\left[\mathrm{~cm}^{3} / \mathrm{dm}^{3}\right]}\end{array}$} & \multicolumn{6}{|c|}{ Dose of iron oxide nanopowder $\left[\mathrm{g} / \mathrm{dm}^{3}\right]$} \\
\hline 1 & 0.00 & 0.01 & 0.02 & 0.03 & 0.04 & 0.05 \\
\hline 3 & 99.3 & 99.0 & 99.3 & 99.0 & 99.1 & 99.1 \\
\hline 5 & 99.6 & 99.6 & 99.6 & 99.5 & 94.2 & 99.6 \\
\hline 7 & 99.9 & 99.8 & 99.9 & 99.9 & 99.9 & 99.9 \\
\hline 100 & 100 & 100 & 100 & 100 & 100 \\
\hline
\end{tabular}

Ferrous sulfate dose $-0.1 \mathrm{~g} / \mathrm{dm}^{3}$, initial absorbance -3.12 (at $525 \mathrm{~nm}$ ), $\mathrm{pH}-3.5$.

Figures 5 and 6 show dependences of COD and TOC removal on iron(II, III) oxide doses. In the case of COD, the optimum iron nano-oxide doses were about $0.02 \mathrm{~g} / \mathrm{dm}^{3}$ irrespective of the amount of hydrogen peroxide added. The TOC reduction was the highest for iron nano-oxide dose of $0.01-0.02 \mathrm{~g} / \mathrm{dm}^{3}$.

Table 2 presents the effect of hydrogen peroxide dosage on wastewater decolorization at a constant dose of iron nano-oxide $-0.03 \mathrm{~g} / \mathrm{dm}^{3}$ and various doses of ferrous sulfate ranging from 0.1 to $0.75 \mathrm{~g} / \mathrm{dm}^{3}$. The wastewater decolorization was high, reaching 96-100\%. The best results of decolorization were achieved at the lowest applied dose of 
ferrous sulfate, i.e. $0.1 \mathrm{~g} / \mathrm{dm}^{3}$. Irrespective of the used doses of ferrous sulfate the wastewater decolorization increased upon increasing hydrogen peroxide dose applied.

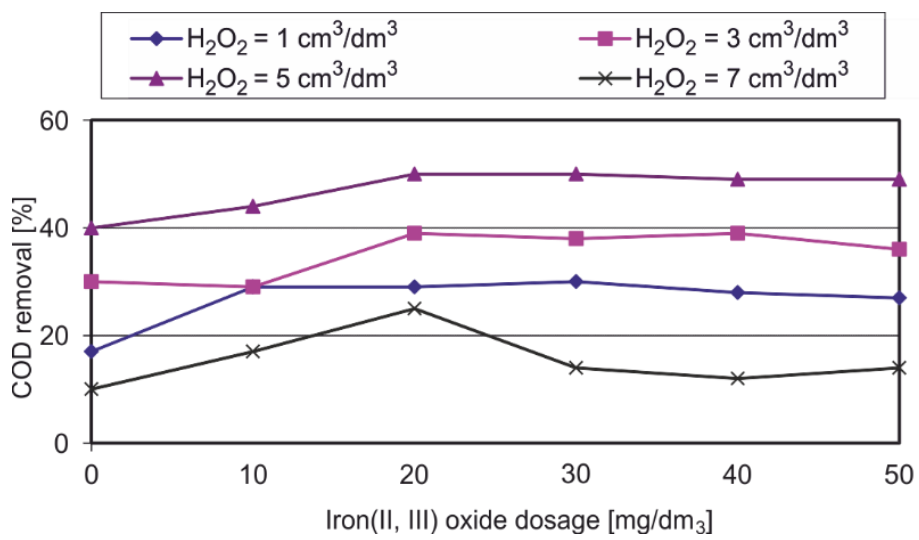

Fig. 5. Effect of iron nano-oxide dosage on COD removal in the wastewater in the nanoFenton process at various quantities of hydrogen peroxide applied in the system: ferrous sulfate dose $-0.1 \mathrm{~g} / \mathrm{dm}^{3}$, initial COD $-305 \mathrm{mg} \mathrm{O} / \mathrm{dm}^{3}, \mathrm{pH}-3.5$

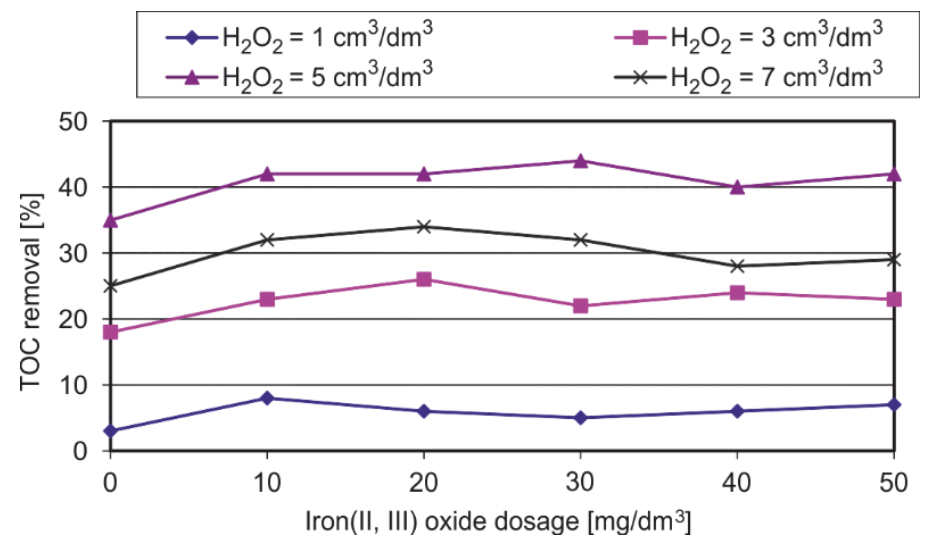

Fig. 6. Effect of iron nano-oxide dosage on TOC removal in the wastewater in the nanoFenton process at various quantities of hydrogen peroxide applied in the system: ferrous sulfate dose $-0.1 \mathrm{~g} / \mathrm{dm}^{3}$, initial TOC $-97 \mathrm{mg} / \mathrm{dm}^{3}, \mathrm{pH}-3.5$

Figures 7 and 8 show the effect of hydrogen peroxide dosage on COD and TOC reduction at a constant dose of iron nano-oxide being $0.03 \mathrm{~g} / \mathrm{dm}^{3}$ and different amounts of ferrous sulfate ranging from 0.1 to $0.75 \mathrm{~g} / \mathrm{dm}^{3}$.

The obtained COD reduction depended on both the amount of hydrogen peroxide applied in the system and the quantity of ferrous sulfate. The most efficient COD reduction was obtained for $0.75 \mathrm{~g} / \mathrm{dm}^{3}$ of ferrous sulfate, being highest applied quantity. The COD reduction lower by several percent was obtained at ferrous sulfate doses of 0.25 
and $0.5 \mathrm{~g} / \mathrm{dm}^{3}$. The COD reduction at a constant dose of ferrous sulfate increased upon increasing amount of hydrogen peroxide applied in the reaction system. The highest COD reduction occurred at $\mathrm{H}_{2} \mathrm{O}_{2}$ dose from 1 to $3 \mathrm{~cm}^{3} / \mathrm{dm}^{3}$. Only for $0.1 \mathrm{~g} / \mathrm{dm}^{3}$ of ferrous sulfate, after a distinct growth of COD reduction at $\mathrm{H}_{2} \mathrm{O}_{2}$ doses from 1 to $5 \mathrm{~cm}^{3} / \mathrm{dm}^{3}$, i.e. from $30 \%$ to $50 \%$, it decreased abruptly to $14 \%$ at $\mathrm{H}_{2} \mathrm{O}_{2}$ dose of $7 \mathrm{~cm}^{3} / \mathrm{dm}^{3}$.

Table 2

Color removal [\%] of wastewater in the nanoFenton process depending on the $\mathrm{FeSO}_{4}$ dose

\begin{tabular}{|c|c|c|c|c|}
\hline \multirow{2}{*}{$\begin{array}{c}\text { Dose of ferrous sulfate } \\
{\left[\mathrm{g} / \mathrm{dm}^{3}\right]}\end{array}$} & \multicolumn{4}{|c|}{$\mathrm{H}_{2} \mathrm{O}_{2}$ dose $\left[\mathrm{cm}^{3} / \mathrm{dm}^{3}\right]$} \\
\cline { 2 - 5 } & 1 & 3 & 5 & 7 \\
\hline 0.10 & 99.0 & 99.5 & 99.9 & 100 \\
\hline 0.25 & 97.1 & 98.7 & 99.3 & 99.7 \\
\hline 0.50 & 96.3 & 98.9 & 99.0 & 99.4 \\
\hline 0.75 & 97.7 & 99.2 & 99.6 & 99.3 \\
\hline
\end{tabular}

Iron nano-oxide dose $-0.03 \mathrm{~g} / \mathrm{dm}^{3}$, initial absorbance -3.12 (wavelength $525 \mathrm{~nm}$ ), $\mathrm{pH}-3.5$.

At the highest dose of ferrous sulfate, the efficiency of TOC reduction was increasing quickly and reached the highest value for $3 \mathrm{~cm}^{3} / \mathrm{dm}^{3}$ of $\mathrm{H}_{2} \mathrm{O}_{2}$, remaining constant for higher doses of $\mathrm{H}_{2} \mathrm{O}_{2}$.

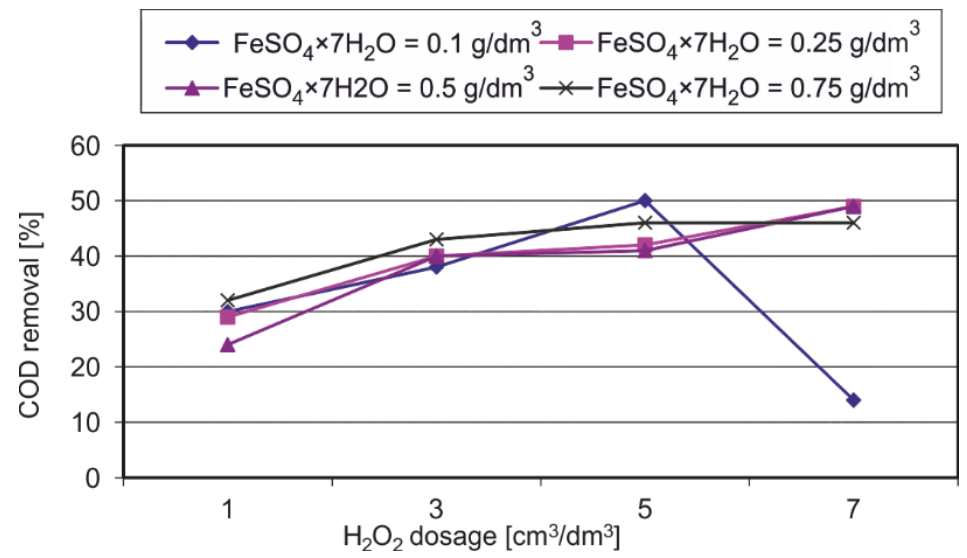

Fig. 7. Effect of hydrogen peroxide dosage on COD removal in the wastewater in the nanoFenton process at various doses of ferrous sulfate: iron nano-oxide dose $-0.03 \mathrm{~g} / \mathrm{dm}^{3}$, initial COD - $305 \mathrm{mg} \mathrm{O}_{2} / \mathrm{dm}^{3}, \mathrm{pH}-3.5$ 


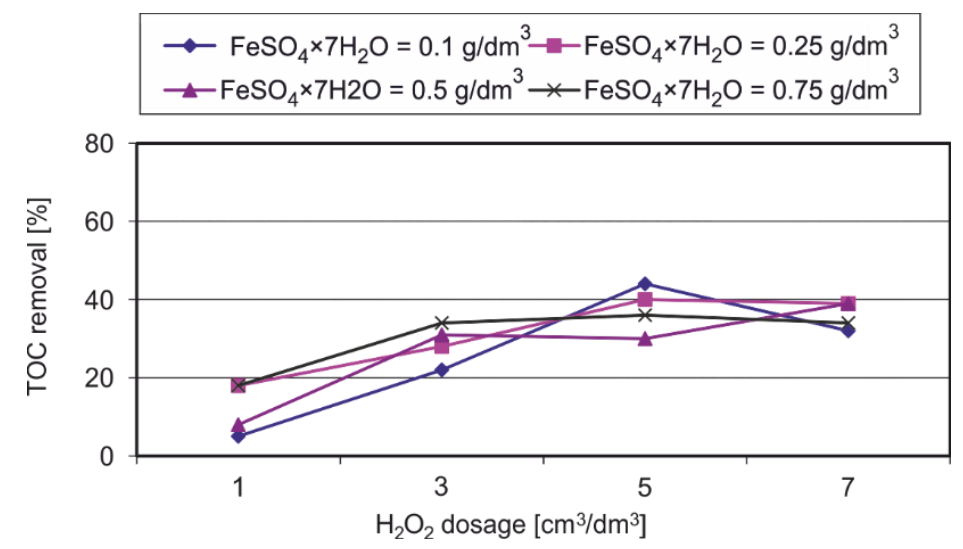

Fig. 8. Effect of hydrogen peroxide dosage on TOC removal in the wastewater in the nanoFenton process at various doses of ferrous sulfate: iron nano-oxide dose $-0.03 \mathrm{~g} / \mathrm{dm}^{3}$, initial TOC $-97 \mathrm{~g} / \mathrm{dm}^{3}, \mathrm{pH}-3.5$

At smaller doses of ferrous sulfate, the COD reduction was further increasing at $\mathrm{H}_{2} \mathrm{O}_{2}$ dose up to $5 \mathrm{~cm}^{3} / \mathrm{dm}^{3}$, while at the highest applied dose of $\mathrm{H}_{2} \mathrm{O}_{2}$, i.e. $7 \mathrm{~cm}^{3} / \mathrm{dm}^{3}$, it stabilized (ferrous sulfate dose of $0.25 \mathrm{~g} / \mathrm{dm}^{3}$ ) or decreased (the lowest ferrous sulfate dose, i.e. $0.1 \mathrm{~g} / \mathrm{dm}^{3}$ ). The use of higher doses of ferrous sulfate at higher doses of hydrogen peroxide significantly hampered the processes of pollutant mineralization in the wastewater. Too high concentration of hydroxyl radicals favors their recombination. Moreover, the TOC reduction was lower than the COD reduction. Thus, the dye decomposition was more efficient than its mineralization. Low-molecular organic compounds with a high degree of oxidation remained in the solution. Hydrogen peroxide doses exceeding $3 \mathrm{~cm}^{3} / \mathrm{dm}^{3}$ at the biggest doses of ferrous sulfate and $\mathrm{H}_{2} \mathrm{O}_{2}$ doses above $5 \mathrm{~cm}^{3} / \mathrm{dm}^{3}$ at the lowest doses of ferrous sulfate were unfavorable. The degree of pollutant reduction in the wastewater did not increase and in some cases it decreased.

The resulting relations are consistent with the data described in the literature with respect to the classical Fenton process [22]. The mechanism of Fenton reaction shows that while using too high doses of hydrogen peroxide beyond a certain limit, the oxidation reaction rate does not increase but decreases. Too high concentration of hydroxyl radicals favors their recombination. Additionally, the likelihood of competitive reactions which do not lead to the oxidation of pollutants increases. As can be seen from the obtained results, a similar mechanism occurs in the Fenton process carried out in the presence of iron nano-oxide.

\subsection{THE EFFECT OF pH OF THE SOLUTION}

An important parameter affecting the Fenton process is $\mathrm{pH}$ of the solution. Therefore, the effect of $\mathrm{pH}$ on the reaction carried out using iron nano-oxide was tested. The 
dose of ferrous sulfate was $0.5 \mathrm{~g} / \mathrm{dm}^{3}$, iron nano-oxide $0.03 \mathrm{~g} / \mathrm{dm}^{3}$ and hydrogen peroxide $5 \mathrm{~cm}^{3} / \mathrm{dm}^{3}$. Figure 9 shows results of changes in COD and TOC reduction in the wastewater depending on the initial $\mathrm{pH}$.

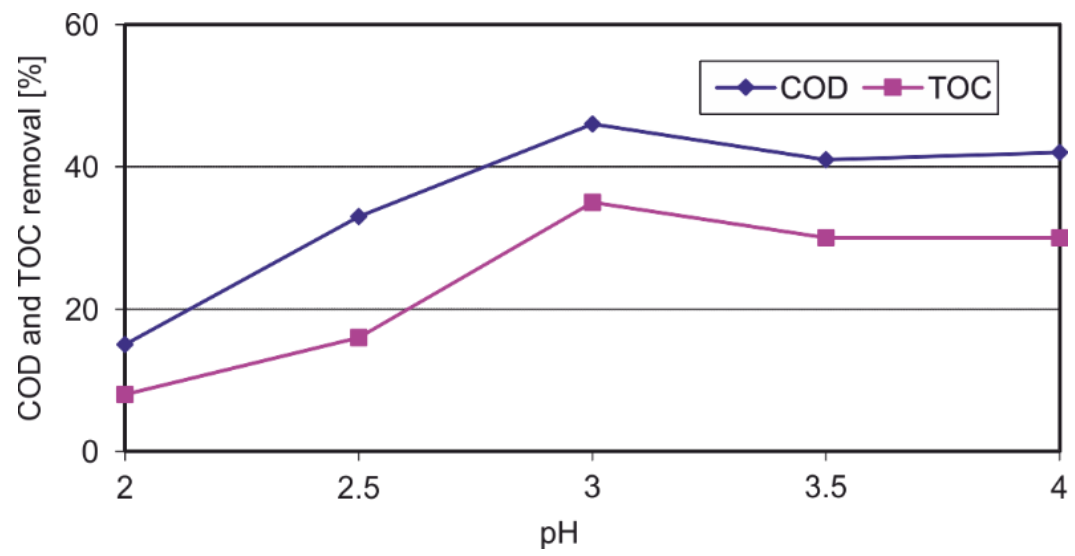

Fig. 9. Effect of $\mathrm{pH}$ on the removal of COD and TOC in wastewater in the nanoFenton process: ferrous sulfate $-0.5 \mathrm{~g} / \mathrm{dm}^{3}$, iron nano-oxide $-0.03 \mathrm{~g} / \mathrm{dm}^{3}$, hydrogen peroxide $-5 \mathrm{~cm}^{3} / \mathrm{dm}^{3}$, initial COD $-305 \mathrm{mg} \mathrm{O} / \mathrm{dm}^{3}$, TOC $-97 \mathrm{mg} / \mathrm{dm}^{3}$

In the case of COD and TOC, similar dependences were obtained. The lowest reduction of both parameters was obtained at $\mathrm{pH}-2$. At $\mathrm{pH}$ increasing from 2 to 3 the reduction of COD increased from $15 \%$ to $46 \%$, while that of TOC from $8 \%$ to $35 \%$. On further increase of $\mathrm{pH}$ to 4 , it remained at a similar level (41-46\% and $30-35 \%$, respectively). The data obtained are in accordance with literature data for the classical Fenton process. For most of the tested compounds the optimum $\mathrm{pH}$ value in the classical Fenton process is about 3 [22]. A decrease of the oxidation efficiency at higher $\mathrm{pH}$ values is caused by the precipitation of iron in the form of hydroxide. It is not recommended either to use too low $\mathrm{pH}$ values since $\mathrm{OH}^{\bullet}$ radicals can react with $\mathrm{H}^{+}$ions which leads to a decrease of their concentration in the solution and reduction of oxidation efficiency of organic compounds.

\subsection{COMPARISON OF THE CLASSICAL FENTON PROCESS AND THE PROCESS WITH THE USE OF IRON NANO-OXIDE}

The efficiencies of pollutant decomposition with the use of iron nanocompounds have been compared with those obtained in a classical Fenton process. The experiments in the classical Fenton process were carried out using hydrogen peroxide doses ranging from 1 to $7 \mathrm{~cm}^{3} / \mathrm{dm}^{3}$ and $\mathrm{FeSO}_{4} \cdot 7 \mathrm{H}_{2} \mathrm{O}$ doses from 0.1 to $0.75 \mathrm{~g} / \mathrm{dm}^{3}$ at $\mathrm{pH}=3.5$. 
Figure 10 shows the efficiencies of the reduction of COD and TOC in the wastewater in the Fenton process carried out using the ferrous sulfate doses of $0.25 \mathrm{~g} / \mathrm{dm}^{3}$ and hydrogen peroxide doses of 1,3 and $5 \mathrm{~cm}^{3} / \mathrm{dm}^{3}(\mathrm{pH}=3.5)$. The nanoFenton process was carried out under similar process parameters with iron nano-oxide doses amounting to $0.03 \mathrm{~g} / \mathrm{dm}^{3}$.
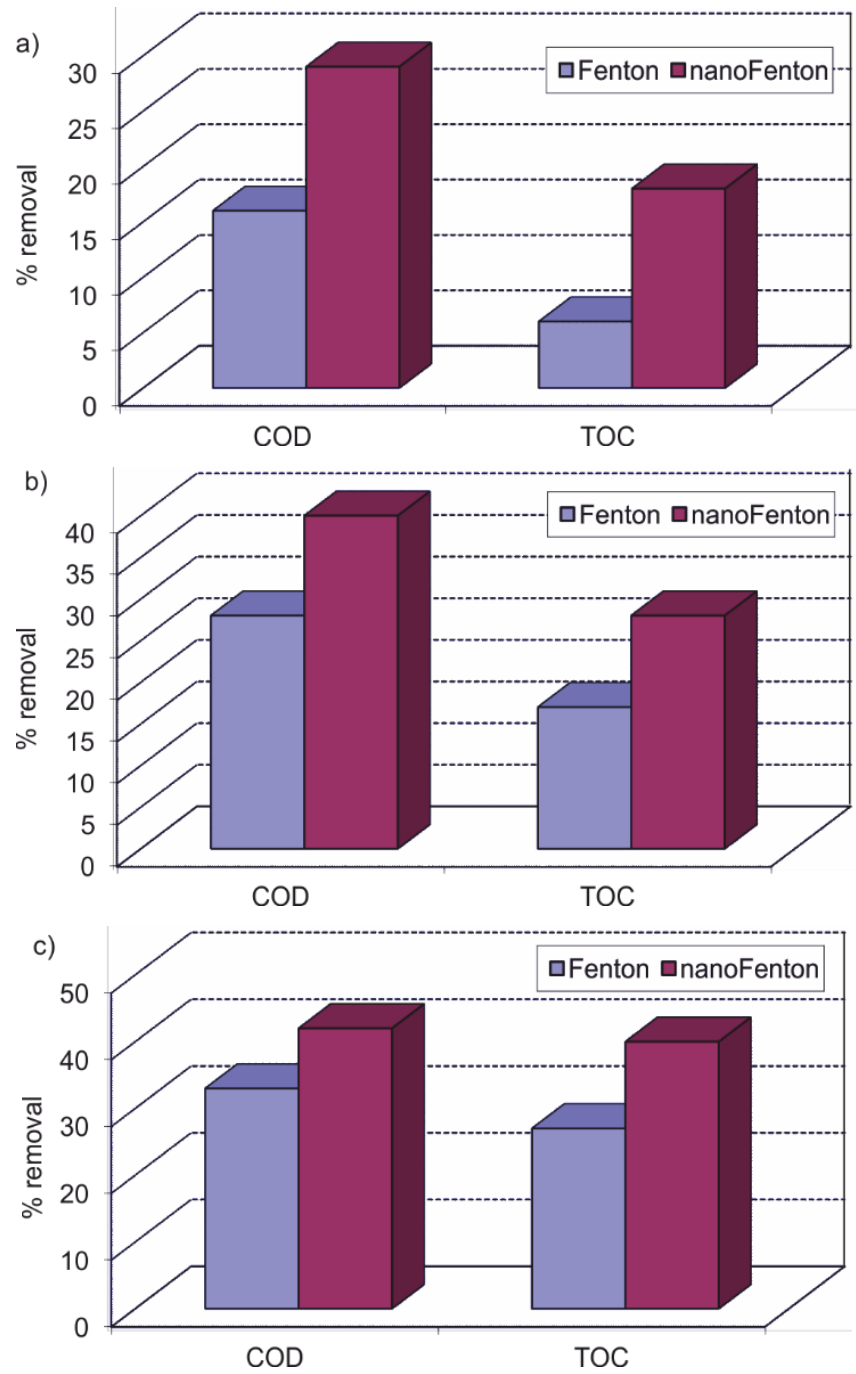

Fig. 10. COD and TOC removal in the wastewater during the Fenton and nanoFenton processes. Fenton process: $\mathrm{pH}-3.5, \mathrm{FeSO}_{4}$ dose $-0.25 \mathrm{~g} / \mathrm{dm}^{3}$, $\mathrm{H}_{2} \mathrm{O}_{2}$ dose $-1 \mathrm{~cm}^{3} / \mathrm{dm}^{3}$ (a), $3 \mathrm{~cm}^{3} / \mathrm{dm}^{3}$ (b), $5 \mathrm{~cm}^{3} / \mathrm{dm}^{3}$ (c). NanoFenton process:

$\mathrm{pH}-3.5 ; \mathrm{FeSO}_{4}$ dose $-0.25 \mathrm{~g} / \mathrm{dm}^{3}$, iron nano-oxide dose $-0.03 \mathrm{~g} / \mathrm{dm}^{3}$, $\mathrm{H}_{2} \mathrm{O}_{2}$ dose $-1 \mathrm{~cm}^{3} / \mathrm{dm}^{3}$ (a), $3 \mathrm{~cm}^{3} / \mathrm{dm}^{3}$ (b), $5 \mathrm{~cm}^{3} / \mathrm{dm}^{3}$ (c) 
The presence of iron nano-oxide improved the performance and efficiency of the Fenton process. At the same dosage of ferrous sulfate and iron nano-oxide the reduction of both COD and TOC increased, depending on the amount of hydrogen peroxide applied in the system. At $\mathrm{H}_{2} \mathrm{O}_{2}$ dose of $1 \mathrm{~cm}^{3} / \mathrm{dm}^{3}$ in the presence of iron nano-oxide the COD reduction increased from 16 to $29 \%$, and TOC from 6 to $18 \%$. At $\mathrm{H}_{2} \mathrm{O}_{2}$ dose of $3 \mathrm{~cm}^{3} / \mathrm{dm}^{3}$, the reduction of COD increased from 28 to $40 \%$ and TOC from 17 to $28 \%$, while at the $\mathrm{H}_{2} \mathrm{O}_{2}$ dose of $5 \mathrm{~cm}^{3} / \mathrm{dm}^{3}$, the reduction of COD increased from 33 to $42 \%$ and TOC from 27 to $40 \%$. The reduction of COD and TOC increased upon increasing the $\mathrm{H}_{2} \mathrm{O}_{2}$ doses. The presence of iron nano-oxide catalyzed the decomposition of pollutants in the wastewater contributing to a significant increase of their mineralization. Depending on the applied process parameters, an increase of COD and TOC reduction from a few to several percent was obtained in the nanoFenton process as compared to the Fenton process.

\section{CONCLUSIONS}

Pollutants in textile wastewater were decomposed in the nanoFenton processes with good efficiency. The decomposition of dyes was complete, with the reduction of COD reaching $51 \%$, and TOC $-44 \%$. The use of iron nano-oxide caused an increase of oxidation efficiency by a few to several percent as compared to that of the classical Fenton process. Iron nano-oxide catalyzed the process of pollutant decomposition improving its efficiency and increasing the mineralization of pollutants.

Results of wastewater treatment depended on the dosage of iron nano-oxide, ferrous sulfate and hydrogen peroxide as well as on $\mathrm{pH}$ of the solution. The oxidation process was most efficient at $\mathrm{pH}$ from 3 to 4 . Optimum doses of iron nano-oxide were low, from 0.01 to $0.02 \mathrm{~g} / \mathrm{dm}^{3}$. Better results of the treatment were obtained at lower doses of ferrous sulfate from 0.1 to $0.25 \mathrm{~g} / \mathrm{dm}^{3}$ and hydrogen peroxide doses not exceeding $5 \mathrm{~cm}^{3} / \mathrm{dm}^{3}$. An additional advantage of the use of lower doses of ferrous sulfate was the minimization of the applied amount of iron(II) which resulted in the formation of smaller amounts of coagulation deposits.

\section{ACKNOWLEDGEMENTS}

The study was financed by the Polish National Science Centre, Project No. N N523 751240.

\section{REFERENCES}

[1] Gottschalk C., Libra J., Saupe A., Ozonation of Water and Waste Water, Wiley, Weinheim, 2000.

[2] Fasnacht M., Blough N., Aqueous photodegradation of polycyclic aromatic hydrocarbons, Environ. Sci. Technol., 2002, 36, 4361. 
[3] Bianco B., De Michelis I., Vegliò F., Fenton treatment of complex industrial wastewater. Optimization of process conditions by surface response method, J. Hazard. Mater., 2011, 186, 1733.

[4] Herrman J., Guillard C., Disdier J., Lehaut C., Malato S., Blanco J., New industrial titania photocatalysts for the solar detoxification of water containing various pollutants, Appl. Catal. B-Environ., 2002, 35, 281.

[5] Rauf M., Salman Ashraf S., Radiation induced degradation of dyes. An overview, J. Hazard. Mater., 2009, 166, 6.

[6] Blanco J., Torrades F., De La Varga M., García-Montaño J., Fenton and biological-Fenton coupled processes for textile wastewater treatment and reuse, Desalination, 2012, 286, 394.

[7] Karthikeyan S., Titus A., Gnanamani A., Mandal A., Sekaran G., Treatment of textile wastewater by homogeneous and heterogeneous Fenton oxidation processes, Desalination, 2011, 281, 438.

[8] Feng F., Xu Z., Li X., You W., Zhen Y., Advanced treatment of dyeing wastewater towards reuse by the combined Fenton oxidation and membrane bioreactor process, J. Environ. Sci., 2010, 22, 1657.

[9] Shyh-FAng K., Chin-Hsaing L., Mon-Chun C., Pre-oxidation and coagulation of textile wastewater by the Fenton process, Chemosphere, 2002, 946, 23.

[10] Kos L., Michalska K., Perkowski J., Textile wastewater treatment by Fenton method, Fibres Text. East. Eur., 2010, 81, 105.

[11] BACH A., ZACH-MaOR A., SEMITA R., Characterization of iron oxide nanocatalyst in mineralization processes, Desalination, 2010, 262, 15.

[12] Xu P., Zeng G., Huang D., Feng C., Hu S., Zhao M., Lai C., Wei Z., Xie G., Liu Z., Use of iron oxide nanomaterials in wastewater treatment. A review, Sci. Total Environ., 2012, 424, 1.

[13] Shin S., Yoo H., Jang J., Polymer-encapsulated iron oxide nanoparticles as highly efficient Fenton catalysts, Catal. Commun., 2008, 10, 178.

[14] ValdÉS-Solís T., VAlle-Vigón P., Sevilla M., Fuertes A., Encapsulation of nanosized catalysts in the hollow core of a mesoporous carbon capsule, J. Catal., 2007, 252, 239.

[15] ZHANG Y., Li Z., SUN W., XIA C., A magnetically recyclable heterogeneous catalyst: Cobalt nanooxide supported on hydroxyapatite-encapsulated $\gamma-\mathrm{Fe}_{2} \mathrm{O}_{3}$ nanocrystallites for highly efficient olefin oxidation with $\mathrm{H}_{2} \mathrm{O}_{2}$, Catal. Commun., 2008, 10, 237.

[16] СHог K., LEE W., Enhanced degradation of trichloroethylene in nano-scale zero-valent iron Fenton system with $\mathrm{Cu}(\mathrm{II})$, J. Hazard. Mater., 2012, 211/212, 146.

[17] GHauch A., TuQAn A., Abou Assi H., Antibiotic removal from water: elimination of amoxicillin and ampicillin by microscale and nanoscale iron particles, Environ. Pollut., 2009, 157, 1626.

[18] Liao Q., Sun J., Gao L., Degradation of phenol by heterogeneous Fenton reaction using multi-walled carbon nanotube supported $\mathrm{Fe}_{2} \mathrm{O}_{3}$ catalysts, Colloid. Surfaces A., 2009, 345, 95.

[19] LiN Y., Weng C., CHEN F., Effective removal of AB24 dye by nano/micro-size zero-valent iron, Sep. Purif. Technol., 2008, 64, 26.

[20] Nie Y., Hu C., Zhou L., Qu J., WeI Q., WANG D., Degradation characteristics of humic acid over iron oxides $/ \mathrm{Fe}^{0}$ core-shell nanoparticles with $\mathrm{UVA} / \mathrm{H}_{2} \mathrm{O}_{2}$, J. Hazard. Mater., 2010, $173,474$.

[21] Kos L., Michalska K., ŻYŁŁa R., Perkowski J., Effect of acetic acid on pollutant decomposition in textile wastewater treated by Fenton method, Environ. Prot. Eng., 2012, 38, 29.

[22] Nowicki L., Godala M., Hydrogen peroxide and Fenton's reaction, [in:] R. Zarzycki (Ed.), Advanced Oxidation Processes in the Environment Protection, Polish Academy of Sciences, Łódź 2002, 81-102 (in Polish). 